\title{
Effect of Gypsum Addition on the Mechanical and Microstructural Performance of Sulphide-Rich Cemented Paste Backfill
}

\author{
Yu Tang ${ }^{1}$, Juanrong Zheng ${ }^{1}$, Lijie Guo ${ }^{2,3, *(\mathbb{D})}$ and Yue Zhao ${ }^{2,3}$ \\ 1 School of Civil Engineering, Zhengzhou University, Zhengzhou 450002, China; tangyu@gs.zzu.edu.cn (Y.T.); \\ zhengjr@zzu.edu.cn (J.Z.) \\ 2 Beijing General Research Institute of Mining and Metallurgy, Beijing 100160, China; zhaoyue@bgrimm.com \\ 3 National Centre for International Research on Green Metal Mining, Beijing 102628, China \\ * Correspondence: guolijie@bgrimm.com
}

Citation: Tang, Y.; Zheng, J.; Guo, L.; Zhao, Y. Effect of Gypsum Addition on the Mechanical and

Microstructural Performance of Sulphide-Rich Cemented

Paste Backfill. Minerals 2021, 11, 283.

https://doi.org/10.3390/min11030283

Academic Editor:

Konstantinos Komnitsas

Received: 3 February 2021

Accepted: 7 March 2021

Published: 9 March 2021

Publisher's Note: MDPI stays neutral with regard to jurisdictional claims in published maps and institutional affiliations.

Copyright: () 2021 by the authors. Licensee MDPI, Basel, Switzerland. This article is an open access article distributed under the terms and conditions of the Creative Commons Attribution (CC BY) license (https:// creativecommons.org/licenses/by/ $4.0 /)$.

\begin{abstract}
The present study investigates the effect of $\beta$-hemihydrate gypsum (HG) dosages on the mechanical and microstructural performance of cemented paste backfill (CPB) produced from sulphide-rich mine tailings using $\mathrm{NaOH}$-activated slag (NAS) as the major binder. X-ray diffraction (XRD), scanning electron microscopy (SEM) and mercury intrusion porosimetry (MIP) analyses were carried out to elucidate the mineralogical composition and microstructure of NAS-HG-CPB samples. The results illustrate that the main hydration products of NAS-HG-CPB from sulphiderich tailings are crystalline $\left(\mathrm{CaSO}_{4} \bullet 2 \mathrm{H}_{2} \mathrm{O}\right.$ and ettringite $\left.(\mathrm{AFt}), 3 \mathrm{CaO} \bullet \mathrm{Al}_{2} \mathrm{O}_{3} \bullet 3 \mathrm{CaSO}_{4} \bullet 32 \mathrm{H}_{2} \mathrm{O}\right)$ and amorphous. The results also show that the $28 \mathrm{~d}$ unconfined compressive strength (UCS) of CPB with 30 wt. \% HG replacing NAS increased by $52 \%$ compared to the UCS of CPB containing no HG, and both have stable long-stage ( $180 \mathrm{~d})$ UCS (i.e., no strength loss). Excess HG addition ( $\geqq 50$ wt. \%) reduced the early-stage ( $\leqq 28 \mathrm{~d}$ ) UCS of NAS-HG-CPB and led to unstable long-stage (180 d) UCS by the formation of secondary gypsum. The use of $30 \mathrm{wt}$ \% HG replacing NAS in NAS-HG-CPB accelerates the hydration process of ground granulated blast furnace slag (GGBS) in the alkaline solution by forming ettringite ( $\mathrm{AFt}$ ), leading to the denser microstructure and improved mechanical performance in comparison with CPB containing no HG. The NAS-HG binder with low dosages of HG ( $\leqq 30$ wt. \%) will be a promising binder for stabilising sulphide and non-sulphide tailings and $\mathrm{CPB}$ production.
\end{abstract}

Keywords: cemented paste backfill; sulphide-rich tailings; $\mathrm{NaOH}$-activated slag; $\beta$-hemihydrate gypsum; strength development

\section{Introduction}

Sulphide-rich tailings are produced during the beneficiation or the treatment of sulphide ores and concentrates. Conventionally, tailings have been deposited into tailings storage facilities, leading to severe environmental, geotechnical and economic problems. Acid mine drainage (AMD) [1,2] is a major environmental and economic hazard influencing the world's mining industry. The sulphide minerals (e.g., pyrite $\mathrm{FeS}_{2}$ ) present in tailings may be oxidised to form an acidic solution when in contact with air (or oxygen) and water. The acidic waters generated can significantly impact the local ecosystem and dissolve the heavy metals present in tailings [3]. The traditional means of mitigating AMD in tailings storage facilities involves the use of water or an impermeable cover to isolate them from the environment. Over the past few decades, cemented paste backfill (CPB) has become a promising alternative method for safe and environmentally responsible tailings disposal [4-6]. CPB is a mixture of dewatered tailings with a solid content between $70 \%$ and $85 \%$, a hydraulic binder (often ordinary Portland cement, OPC) and water (fresh and/or mine processed). The mixed CPB slurry may then be pumped into mined cavities to form support systems and working platforms $[7,8]$. 
The mechanical performance of CPB is governed by various influencing factors. While non-ferrous mine tailings are used in backfill operations, the high sulphide content may influence CPB's durability, especially when ordinary Portland cement (OPC) is used as the binder. Sulphates $\left(\mathrm{SO}_{4}{ }^{2-}\right)$ and acidity resulting from the oxidation of sulphide minerals (i.e., pyrite) in the presence of water and air may cause potential durability problems (i.e., strength loss) in CPB. The reaction between sulphates and the cement hydration product $\left(\mathrm{Ca}(\mathrm{OH})_{2}\right)$ generates secondary gypsum $\left(\mathrm{CaSO}_{4} \bullet 2 \mathrm{H}_{2} \mathrm{O}\right)$ and ettringite $(\mathrm{AFt})$ with highly expansive properties, which may lead to the formation of micro-cracks in $\mathrm{CPB}$, thus reducing the CPB's strength and stability $[9,10]$. Additionally, the acidity generated by the oxidation of sulphide minerals weakens the C-S-H gels and portlandite, eventually reducing CPB stability [11,12]. In order to solve this problem, alkali-activated slag (AAS) has been utilised as an alternative binder to OPC. Compared to OPC, AAS cement is more durable against acid and sulphate attack [13-16].

On the other hand, a large amount of waste gypsum (i.e., phosphogypsum, fluor gypsum and flue gas desulphurisation (FGD) gypsum) tends to cause serious problems, such as land occupation, water pollution, particulate pollution and ecological destruction [17-19]. Very careful management is required if phosphogypsum is to be used as a construction material or fertiliser, because it can exhibit radioactivity [20], and contains soluble salt [21] and harmful impurities such as fluorides and phosphates [22]. In general, only modified phosphogypsum can be used as a construction material [23-25]. At present, a considerable amount of waste gypsum is disposed of at landfills. Peyronnard et al. [26] investigated the possibility of reusing waste gypsum for supplementary cementitious materials in mine backfill. The researchers demonstrated that the CPB formed using $4.5 \mathrm{wt}$. \% binders (40\% PC $-36 \%$ waste glass $-24 \%$ anhydrite (fluor gypsum)) mixed with mining waste could produce a unconfined compressive strength (UCS) of $0.6 \mathrm{MPa}$ after 14 days of curing. Jiang et al. [27] used hemihydrate phosphogypsum and quicklime to prepare a low-cost filling binder, finding that the $3 \mathrm{~d}$ and $28 \mathrm{~d}$ UCS of the filling body mixed by the filling binder and the addition of $0-160 \%$ tailings in hemihydrate phosphogypsum was between 2 and $9 \mathrm{MPa}$, which can meet the strength requirements of various mining methods. $\beta$-hemihydrate gypsum can be obtained by calcining waste gypsum at about $125^{\circ} \mathrm{C}$.

In recent years, it has been reported that the use of AAS can produce CPB with higher long-stage $(360 \mathrm{~d})$ strength and stronger resistance to aggressive media [28]. However, the early age ( $\leqq 28 \mathrm{~d})$ strength of CPBs using AAS as binders is lower. The activation of ground granulated blast furnace slag (GGBS) by sulfates has been deeply studied by some researchers in the field of building materials. For example, super-sulfated cements (SSCs) are binders comprising ground granulated blast furnace slag (GGBS), generally present at levels higher than $80 \%$, calcium sulfate (10-20\%) and small quantities of activator, which can be Portland cement (or clinker), or even other alkaline activators, such as lime or potassium hydroxide [29]. The proposed system in this study differs from SSC-based building materials because it includes higher water-solid ratios and a lower binder dosage. At present, there are no studies on the effect of $\beta$-hemihydrate gypsum (HG) dosages on the properties of CPB from sulphide-rich mine tailings using $\mathrm{NaOH}$-activated slag (NAS) as binders.

In order to increase the early-stage strength of CPB using NAS as binders and effectively recycle waste gypsum to solve the environmental problem, the effect of $\beta$ hemihydrate gypsum dosages on the mechanical performance and microstructure of CPB using $\mathrm{NaOH}$-activated slag as binders is investigated in the current study. A series of X-ray diffraction (XRD), scanning electron microscope (SEM) and mercury intrusion porosimetry (MIP) analyses was carried out to elucidate the mineralogical composition and microstructure of CPB samples associated with mechanical performance. 


\section{Materials and Test Methods}

\subsection{Test Raw Materials}

\subsubsection{Tailings}

About $500 \mathrm{~kg}$ of wet tailings containing approximately $25 \mathrm{wt}$. \% of water was sourced from a lead-zinc mine in Southern China, and was used in the present study. The particle size distribution (PSD) of the tailings was determined by a BT-9300H particle size analyser (Dandong baite instruments Co., Ltd., Dandong, China). As shown in Table 1, in terms of grain-size distribution, the tailings consisted of $48.85 \%$ fine particles $(<20 \mu \mathrm{m})$, and their size is classified as medium [30].

Table 1. Physical properties of tailings and HG andGGBS used.

\begin{tabular}{|c|c|c|c|c|c|}
\hline $\begin{array}{c}\text { Physical } \\
\text { Properties }\end{array}$ & $\begin{array}{l}\mathrm{SSA}^{(a)} \\
\left(\mathrm{m}^{2} / \mathrm{kg}\right)\end{array}$ & $>100 \mu \mathrm{m}$ (wt. \%) & $>45 \mu \mathrm{m}$ (wt. \%) & $\begin{array}{c}\text { D50 } \\
(\mu \mathrm{m})\end{array}$ & $<20 \mu \mathrm{m}$ (wt. \%) \\
\hline Tailings & 668.7 & 19.0 & 35.8 & 21.3 & 48.8 \\
\hline GGBS & 681.5 & 0 & 3.3 & 9.8 & 76.4 \\
\hline HG & 339.2 & 3.6 & 36.3 & 34.2 & 31.3 \\
\hline
\end{tabular}

(a) SSA is the specific surface area.

The metal ion (i.e., $\mathrm{Fe}, \mathrm{Pb}, \mathrm{Cu}, \mathrm{Zu}$ ) content of tailings was determined with the use of atomic absorption spectroscopy (AAS). Other chemical elements were determined according to the methods specified in the Chinese standards: GB/T 176-2017 (methods for chemical analysis of cement). The chemical composition of the tailings is provided in Table 2. The sulfur content of the tailings is $21.09 \mathrm{wt} . \%$, and is considered high [31]. An X-ray diffractometer was used to analyse the mineralogical phases of raw tailings. The results in Figure 1a indicate that the only sulphide phase in the sampled tailings is pyrite, while the other mineralogical phases are quartz, calcite, dolomite, and muscovite.

Table 2. Chemical properties of tailings, GGBS and HG used.

\begin{tabular}{cccccccccc}
\hline $\begin{array}{c}\text { Chemical } \\
\begin{array}{c}\text { Composition } \\
\text { (wt. } \% \text { ) }\end{array}\end{array}$ & $\mathrm{SiO}_{2}$ & $\mathrm{Al}_{\mathbf{2}} \mathbf{O}_{\mathbf{3}}$ & $\mathbf{F e}_{\mathbf{t}}{ }^{(\mathbf{a})}$ & $\mathbf{C a O}$ & $\mathbf{M g O}$ & $\mathbf{P b}$ & $\mathbf{C u}$ & $\mathbf{Z n}$ & $\mathbf{S}$ \\
\hline Tailings & 11.23 & 2.65 & 19.80 & 20.06 & 0.40 & 0.90 & 0.46 & 0.45 & 21.09 \\
GGBS & 31.68 & 12.77 & 2.89 & 40.8 & 4.76 & - & - & - & 0.85 \\
HG & 0.98 & 0.50 & - & 34.68 & 0.26 & - & - & - & 17.1 \\
\hline
\end{tabular}

(a) $\mathrm{Fe}_{\mathrm{t}}$ is the total $\mathrm{Fe}$ content in dry tailings and GGBS.

\subsubsection{Binders and the Mixing Water}

In this present study, $\mathrm{NaOH}$-activated slag (i.e., ground granulated blast furnace slag (GGBS)) mixed with different contents of $\beta$-hemihydrate gypsum was used as the binder. The chemical properties of GGBS and HG were tested according to the methods specified in the Chinese standards: GB/T 176-2017 (methods for chemical analysis of cement) and GB/T 5484-2000 (methods for chemical analysis of gypsum), respectively. The GGBS is a grade S95 product sourced from the local market. Its physical and chemical properties are presented in Tables 1 and 2. The mineralogical analysis of GGBS, shown in Figure 1b, indicates that the GGBS has a glassy phase structure.

Pure chemical reagent $\mathrm{NaOH}$ was used as an alkali-activator in this study, sourced from Shanghai Sinopharm Chemical Reagent Co., Ltd., Shanghai, China. The gypsum used in this study was $\mathrm{HG}\left(\mathrm{CaSO}_{4} \bullet 0.5 \mathrm{H}_{2} \mathrm{O}\right)$ (see Figure $1 \mathrm{c}$ ), a commercial product produced by calcining FGD at $\sim 125^{\circ} \mathrm{C}$. The physical and chemical properties of HG are shown in Tables 1 and 2.

Pure chemical reagent citric acid, sourced from Shanghai Sinopharm Chemical Reagent Co., Ltd., was used as a retarder.

Tap water was used for the CPB preparations. 

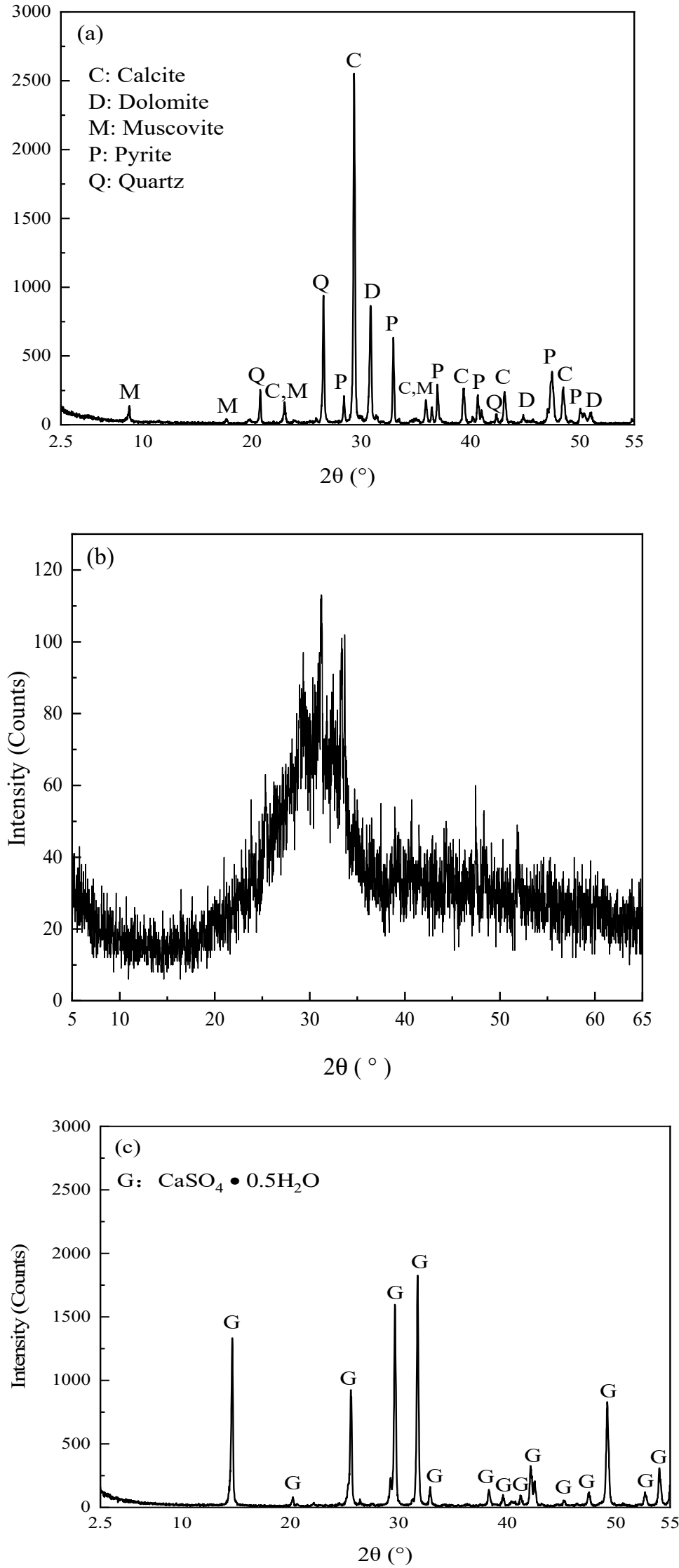

Figure 1. The X-ray diffraction (XRD) profiles of tailings (a), GGBS (b) and HG (c). 


\subsection{Test Methods}

\subsubsection{Mix Designs and Sample Preparations}

In this study, a total of 10 mix designs, as outlined in Table 3, were examined. In order to maintain the same rheological properties in all different mix designs, the solid content (or water content) of each mix was designed to achieve the same fluidity test value $(180 \mathrm{~mm})$.

Table 3. Mix designs and their properties.

\begin{tabular}{|c|c|c|c|c|c|c|c|}
\hline Pastes & $\begin{array}{c}\text { Tailings } \\
\text { (Dry Mass) } \\
\text { (wt. \%) }\end{array}$ & $\begin{array}{c}\text { GGBS } \\
\text { (wt. \%) }\end{array}$ & $\begin{array}{c}\mathrm{NaOH} \\
\text { (wt. \%) }\end{array}$ & $\begin{array}{l}\text { HG (a) } \\
\text { (wt. \%) }\end{array}$ & $\begin{array}{c}\text { Solid } \\
\text { Content } \\
\text { (wt. \%) }\end{array}$ & $\begin{array}{c}\mathrm{NaOH}^{(b)} \\
(\mathrm{mol} / \mathrm{L})\end{array}$ & $\begin{array}{c}\text { Fluidity } \\
\text { (mm) }\end{array}$ \\
\hline NAS-HG0 & - & 97 & 3 & - & 71.4 & 2.62 & 180 \\
\hline NAS-HG30 & - & 67.9 & 2.1 & 30 & 72.7 & 1.92 & 180 \\
\hline NAS-HG50 & - & 48.5 & 1.5 & 50 & 72.9 & 1.38 & 180 \\
\hline NAS-HG70 & - & 29.1 & 0.9 & 70 & 71.8 & 0.8 & 180 \\
\hline NAS-HG100 & - & - & - & 100 & 69.3 & - & 180 \\
\hline $\begin{array}{c}\text { B14NAS- } \\
\text { HG0 }\end{array}$ & 86 & 13.58 & 0.42 & - & 73.7 & 0.4 & 180 \\
\hline $\begin{array}{c}\text { B14NAS- } \\
\text { HG30 }\end{array}$ & 86 & 9.51 & 0.29 & 4.2 & 73.9 & 0.28 & 180 \\
\hline $\begin{array}{c}\text { B14NAS- } \\
\text { HG50 }\end{array}$ & 86 & 6.79 & 0.21 & 7.0 & 73.9 & 0.2 & 180 \\
\hline $\begin{array}{c}\text { B14NAS- } \\
\text { HG70 }\end{array}$ & 86 & 4.07 & 0.13 & 9.8 & 73.8 & 0.12 & 180 \\
\hline B14-HG100 & 86 & - & - & 14 & 73.4 & - & 180 \\
\hline
\end{tabular}

(a) HG had 0.15 wt. \% citric acid as a retarder; ${ }^{(b)} \mathrm{NaOH}(\mathrm{mol} / \mathrm{L})$ is the molarity of the $\mathrm{NaOH}$ in the water of the fresh pastes.

According to the mixture proportions shown in Table 3, raw materials, including tailings, GGBS, NaOH, HG and the retarder, were mixed using a laboratory cement mortar blender for approximately $5 \mathrm{~min}$ to obtain homogenised pastes. The pastes were subjected to a fluidity test, then poured into cubic $(40 \times 40 \times 40 \mathrm{~mm})$ moulds. The prepared specimens were sealed and cured at a temperature of $20 \pm 2{ }^{\circ} \mathrm{C}$ and a relative humidity of $90 \pm 2 \%$ for three days before demolding.

\subsubsection{Fluidity Tests}

Fluidity tests were carried out for both fresh NAS-HG-CPB pastes and the same pastes after resting for one hour. The pastes were initially poured into the micro-slump cone (height $\times$ upper diameter $\times$ lower diameter $=60 \times 70 \times 100(\mathrm{~mm})$ ) on the centre of the electric jump table specified by the Chinese standard (GB/T 2419-2005). After lifting the micro-slump cone vertically and shaking the electric jump table five times, the spread diameter of the paste can be recorded as the fluidity of the paste.

The $180 \mathrm{~mm}$ fluidity value measured by the above fluidity tests corresponds to the $180 \mathrm{~mm}$ slump value measured by the slump cone (height $\times$ upper diameter $\times$ lower diameter $=300 \times 100 \times 200(\mathrm{~mm}))$ according to the Chinese standard (GB/T 50080-2002) [32].

\subsubsection{Unconfined Compressive Strength (UCS)}

UCS is a widely accepted and essential property of CPB for controlling the quality of the backfill. UCS tests, in triplicate, were conducted at the predetermined curing periods ( 3 days, 7 days, 14 days, 28 days, 56 days, 120 days and 180 days) by a digital display pressure testing machine (YWE-300, Wuxi Xiwei Test Instruments Corporation, Wuxi, China) with a maximum capacity of $300 \mathrm{kN}$ (see Figure 2). According to the cement mortar strength test methods (ISO) (GB17671-1999), the actual compression area of the test sample should be measured. 


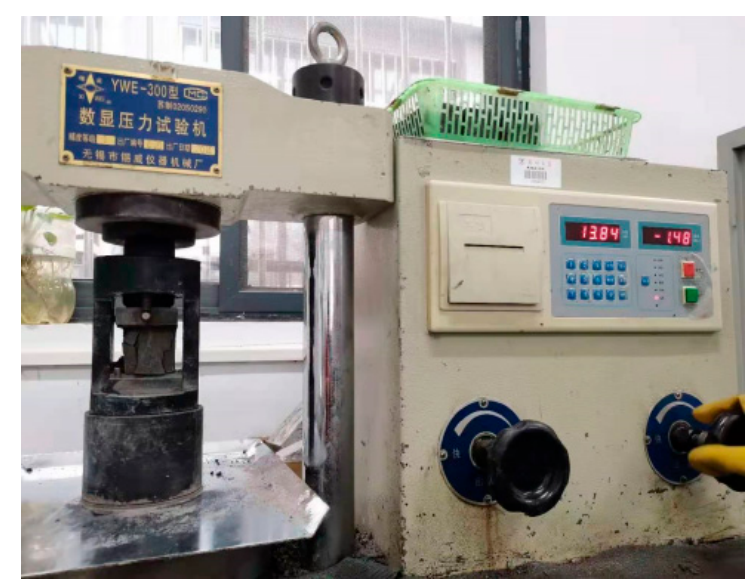

Figure 2. Digital display pressure testing machine.

\subsubsection{XRD, SEM and MIP Analyses}

After the UCS test, the representative specimens (including both the surfaces and the centres of the test samples) were stored in ethanol to arrest the hydration process, and then were dried at a low temperature (about $65^{\circ} \mathrm{C}$ to assess the constant weight for XRD, SEM and MIP analyses.

X-ray diffraction analyses were used to identify crystalline hydration products. XRD was carried out on the D/Max-2500 PC X-ray diffractometer (Rigaku Corporation, Tokyo, Japan) using a scanning range from $2.5^{\circ}$ to $55^{\circ}(2 \theta)$, with a scanning speed of $2^{\circ} / \mathrm{min}$. The microstructure of the samples was examined under a JSM-7500F (NIDEC Corporation, Tokyo, Japan) field emission scanning electron microscope operated at $10 \mathrm{kV}$ accelerating voltage. The pore size distribution and total porosity were evaluated using the AutoPore IV9500 V1.09 (made in China) according to the GB/T 21650.1-2008. The mercury injection apparatus pressed $0.485 \mathrm{~N} / \mathrm{m}$.

\section{Results and Discussion}

\subsection{Effects of HG Dosage on the Fluidity of NAS-HG-CPB Pastes}

The effects of HG dosage on the fluidity values of fresh NAS-HG-CPB pastes rested for one hour are shown in Table 4.

Table 4. The fluidity of fresh NAS-HG-CPB pastes resting for $1 \mathrm{~h}$.

\begin{tabular}{|c|c|c|c|c|c|c|c|}
\hline Pastes & $\begin{array}{c}\text { Tailings } \\
\text { (Dry Mass) } \\
\text { (wt. \%) }\end{array}$ & $\begin{array}{c}\text { GGBS } \\
\text { (wt. \%) }\end{array}$ & $\begin{array}{l}\mathrm{NaOH} \\
\text { (wt. \%) }\end{array}$ & $\begin{array}{l}\text { HG }^{(a)} \\
(w t . \%)\end{array}$ & $\begin{array}{c}\text { Solid } \\
\text { Content } \\
\text { (wt. \%) }\end{array}$ & $\begin{array}{l}\text { Fluidity } \\
\text { (mm) }\end{array}$ & $\begin{array}{l}\text { Fluidity } \\
\text { (1 h) }(\mathrm{mm})\end{array}$ \\
\hline B14NAS-HG0 & 86 & 13.58 & 0.42 & - & 73.7 & 180 & 180 \\
\hline B14NAS-HG30 & 86 & 9.51 & 0.29 & 4.2 & 73.9 & 180 & 153 \\
\hline B14NAS-HG50 & 86 & 6.79 & 0.21 & 7.0 & 73.9 & 180 & 139 \\
\hline B14NAS-HG70 & 86 & 4.07 & 0.13 & 9.8 & 73.8 & 180 & 125 \\
\hline B14-HG100 & 86 & - & - & 14 & 73.4 & 180 & 144 \\
\hline
\end{tabular}

(a) HG had $0.15 \%$ citric acid as a retarder.

From the results in Table 4 we can see that, with the increase in HG dosages, the fluidity values of fresh NAS-HG-CPB pastes are stable. In contrast, the fluidity values of the NAS-HG-CPB pastes after resting for one hour decreased with the increase in HG dosages, which is probably caused by the rapid reaction between HG and water.

\subsection{Effects of HG Dosages on UCS of NAS-HG-CPB}

The UCS development of NAS-HG-CPB with different HG dosages is shown in Figure 3. As shown in Figure 3, the $3 \mathrm{~d}$ and $7 \mathrm{~d}$ UCS values of CPB with B14NASHG0 binder are 2.0 MPa and 5.2 MPa, respectively, and the $28 \mathrm{~d}$ and $180 \mathrm{~d}$ UCS values 
are 6.9 MPa and 10.4 MPa, respectively. The early-stage ( $3 \mathrm{~d}$ and $7 \mathrm{~d}$ ) UCS values of CPB with B14NAS-HG30 binder are lower, but the UCS values of CPB after curing for $7 \mathrm{~d}$ are higher than those of CPB with B14NAS-HG0. The $28 \mathrm{~d}$ and $180 \mathrm{~d}$ UCS values of CPB with B14NAS-HG30 are 10.5 MPa and 11.3 MP. This means that the $28 \mathrm{~d}$ UCS values of CPB with 30 wt. \% HG replacing NAS (i.e., B14NAS-HG30) were increased by $52 \%$ compared to $\mathrm{CPB}$ without $\mathrm{HG}$ incorporation (i.e., B14NAS-HG0), and both have stable long-stage (180 d) UCS (i.e., no strength loss).

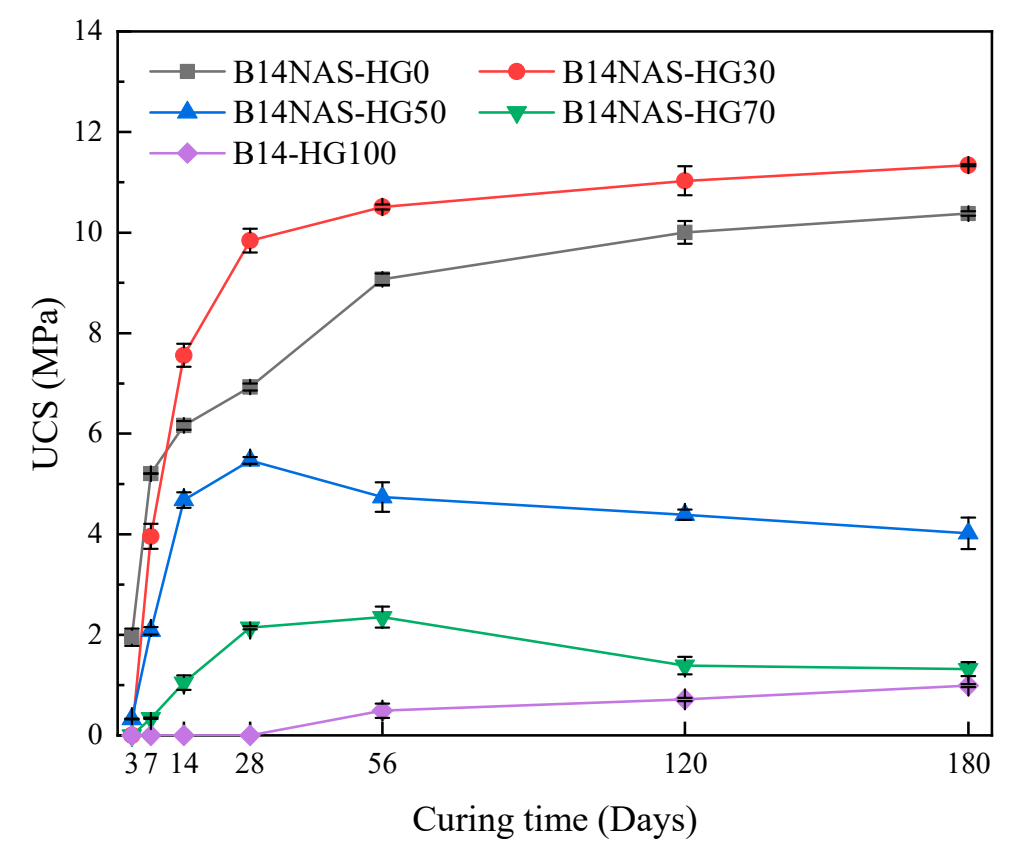

Figure 3. The unconfined compressive strength (UCS) development of NAS-HG-CPB with different HG dosages.

When the HG dosage is $50 \mathrm{wt}$. \%, the UCS values of CPB after curing for $28 \mathrm{~d}$ decreased gradually. The $28 \mathrm{~d}$ UCS of CPB with B14NAS-HG50 binder is $5.5 \mathrm{MPa}$, but the $180 \mathrm{~d}$ UCS is $4.0 \mathrm{MPa}$, which decreased by $27.3 \%$ compared with the $28 \mathrm{~d}$ UCS. When the HG content is $70 \mathrm{wt}$. \%, its $28 \mathrm{~d}$ UCS is $2.1 \mathrm{MPa}$, while its $180 \mathrm{~d}$ UCS is $1.3 \mathrm{MPa}$, which decreases by $38.1 \%$ compared with $28 \mathrm{~d}$ UCS. As for HG-CPB formed using pure HG as the binder, there is no UCS in the early-stage (within $28 \mathrm{~d}$ ), but with the increase in curing time, the $180 \mathrm{~d}$ UCS value of HG-CPB reached 1.0 MPa.

\subsection{Mineralogical Composition and Microstructure Analyses}

\subsubsection{XRD Analyses}

Figure 4 shows the XRD profiles of NAS-HG pastes and NAS-HG-CPB after $28 \mathrm{~d}$ of curing.

As shown in Figure 4a, the major hydration products of the NAS paste are amorphous phases (i.e., amorphous hydrated products and unreacted GGBS) and crystalline (hydrotalcite-like, $\mathrm{Ht}$ ). With the addition of HG, the major hydration products of NAS-HG pastes become crystalline products $\left(\mathrm{CaSO}_{4} \bullet 2 \mathrm{H}_{2} \mathrm{O}\right.$ and ettringite) and amorphous hydration products. With the increase in $\mathrm{HG}$ incorporation, the crystalline products $\left(\mathrm{CaSO}_{4} \bullet 2 \mathrm{H}_{2} \mathrm{O}\right.$ and ettringite) also increased, and the amorphous hydration products decreased. 

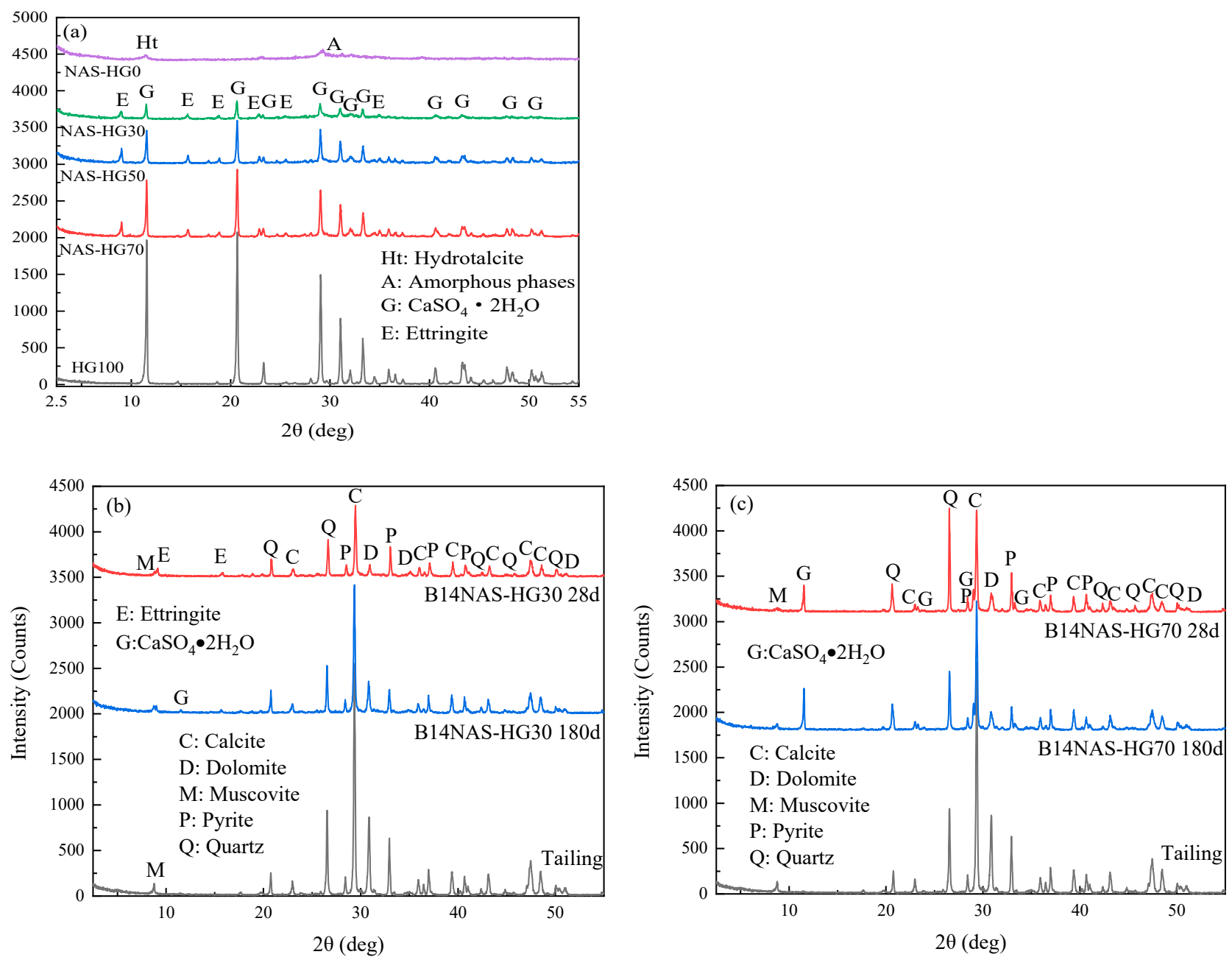

Figure 4. XRD profiles of NAS-HG pastes (a) and NAS-HG-CPB (b,c).

As demonstrated in Figure $4 b$, the hydration product ettringite (AFt) in CPB-28d with B14NAS-HG30 binder was detected compared to the tailings. The formation of AFt consumed the hydration product $\mathrm{CaSO}_{4} \bullet 2 \mathrm{H}_{2} \mathrm{O}$, and the high spectrum peaks of the tailings and the overlaps of the spectral lines meant the $\mathrm{CaSO}_{4} \bullet 2 \mathrm{H}_{2} \mathrm{O}$ was undetected. There is a weak secondary gypsum $\left(\mathrm{CaSO}_{4} \bullet 2 \mathrm{H}_{2} \mathrm{O}\right)$ peak in the XRD pattern of CPB-180d with B14NAS-HG30 binder, but no strength loss is noticed.

As shown in Figure $4 \mathrm{c}$, the hydration product $\mathrm{CaSO}_{4} \cdot 2 \mathrm{H}_{2} \mathrm{O}$ in $\mathrm{CPB}-28 \mathrm{~d}$ with a B14NAS-HG70 binder was detected. Moreover, the diffraction peak of $\mathrm{CaSO}_{4} \bullet 2 \mathrm{H}_{2} \mathrm{O}$ in CPB-180d with a B14NAS-HG70 binder is significantly enhanced, and a 38.1\% strength loss is seen when the curing period is increased from 28 to $180 \mathrm{~d}$, due to secondary gypsum formation. Whether the sulphide present in the tailings is involved in the formation of secondary gypsum should be the subject of further investigation.

This could imply that the main hydration products of NAS-HG-CPB are crystalline $\left(\mathrm{CaSO}_{4} \cdot 2 \mathrm{H}_{2} \mathrm{O}\right.$, ettringite (AFt)) and amorphous hydrated products, as compared with those of NAS-HG pastes.

\subsubsection{SEM Analyses}

Figure 5 shows the SEM profile of CPB-28d with B14NAS-HG0, B14NAS-HG30 and B14NAS-HG70 binder, respectively. 

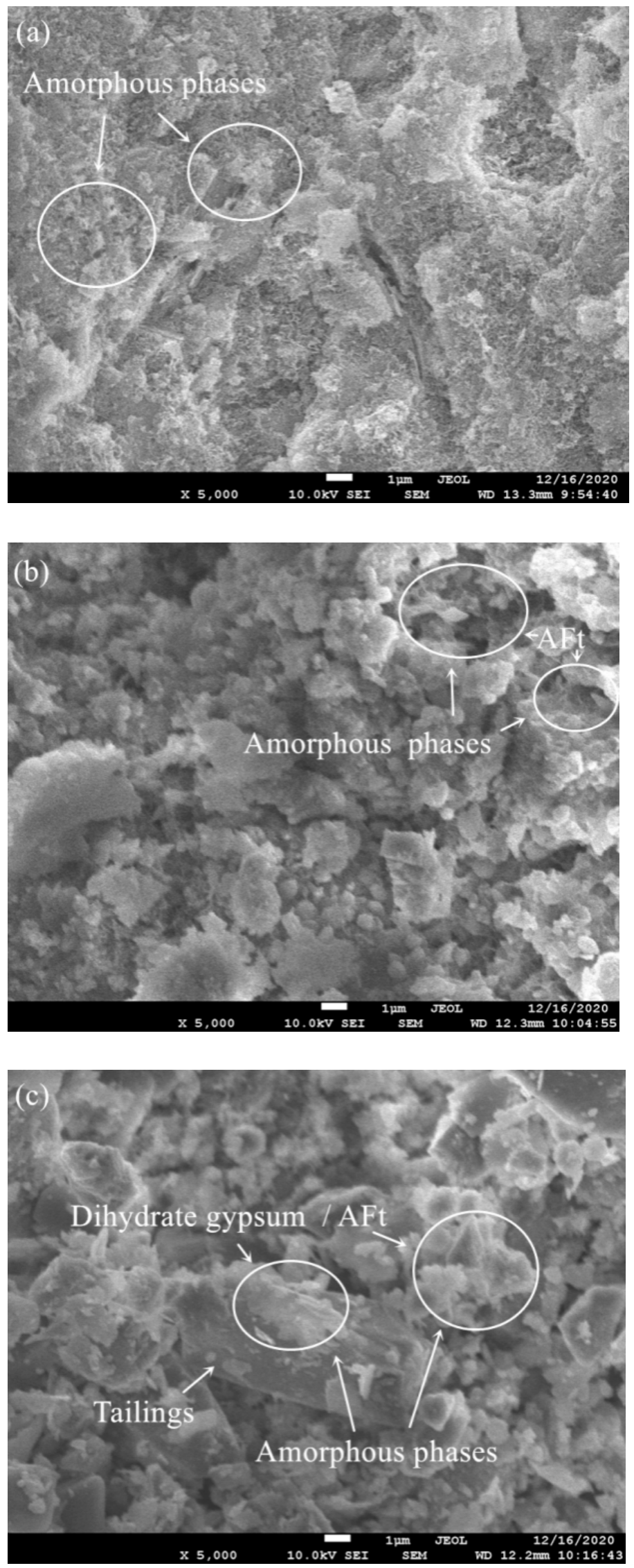

Figure 5. SEM micrograph of B14NAS-HG0 (a), B14NAS-HG30 (b) and B14NAS-HG70 (c) at $28 \mathrm{~d}$. 
As demonstrated in Figure 5a, amorphous products are present in CPB-28d with B14NAS-HG0 binder, and the edge of the tailings is invisible. Figure $4 \mathrm{~b}$ shows that the hydration products consisted mainly of amorphous hydration products intermixed with minor amounts of crystalline hydration products (i.e., ettringite), which are different from the microstructure in CPB-28d with B14NAS-HG0 binder. As a result, the incorporation of appropriate HG significantly enhanced the $14 \mathrm{~d}$ and $28 \mathrm{~d}$ UCS of the NAS-HG-CPB samples compared with the NAS-CPB samples. Figure 4c shows that for CPB-28d with a B14NAS-HG70 binder, the edge of the tailings is visible, and the hydration product $\mathrm{CaSO}_{4} \bullet 2 \mathrm{H}_{2} \mathrm{O}$ is coated with amorphous hydration products scattered among the tailings particles, resulting in the loose microstructure that leads to the low UCS.

\subsubsection{MIP Analyses}

Figure 6 shows the cumulative porosity and differential porosity of NAS-HG-CPB at $180 \mathrm{~d}$. Figure 6a shows that the total porosity of CPB-180d with a B14NAS-HG0 binder is $35.4 \%$, and its corresponding UCS is $10.4 \mathrm{MPa}$. With the addition HG of $30 \mathrm{wt}$. \%, the total porosity becomes $33.7 \%$, and the corresponding UCS is $11.3 \mathrm{MPa}$. With the further addition of HG, the total porosity of CPB-180 with B14NAS-HG50 binder is $36.0 \%$, and the corresponding UCS is $4.0 \mathrm{MPa}$. The results show that the $180 \mathrm{~d}$ UCS of NAS-HG-CPB has a negative correlation with the total porosity.
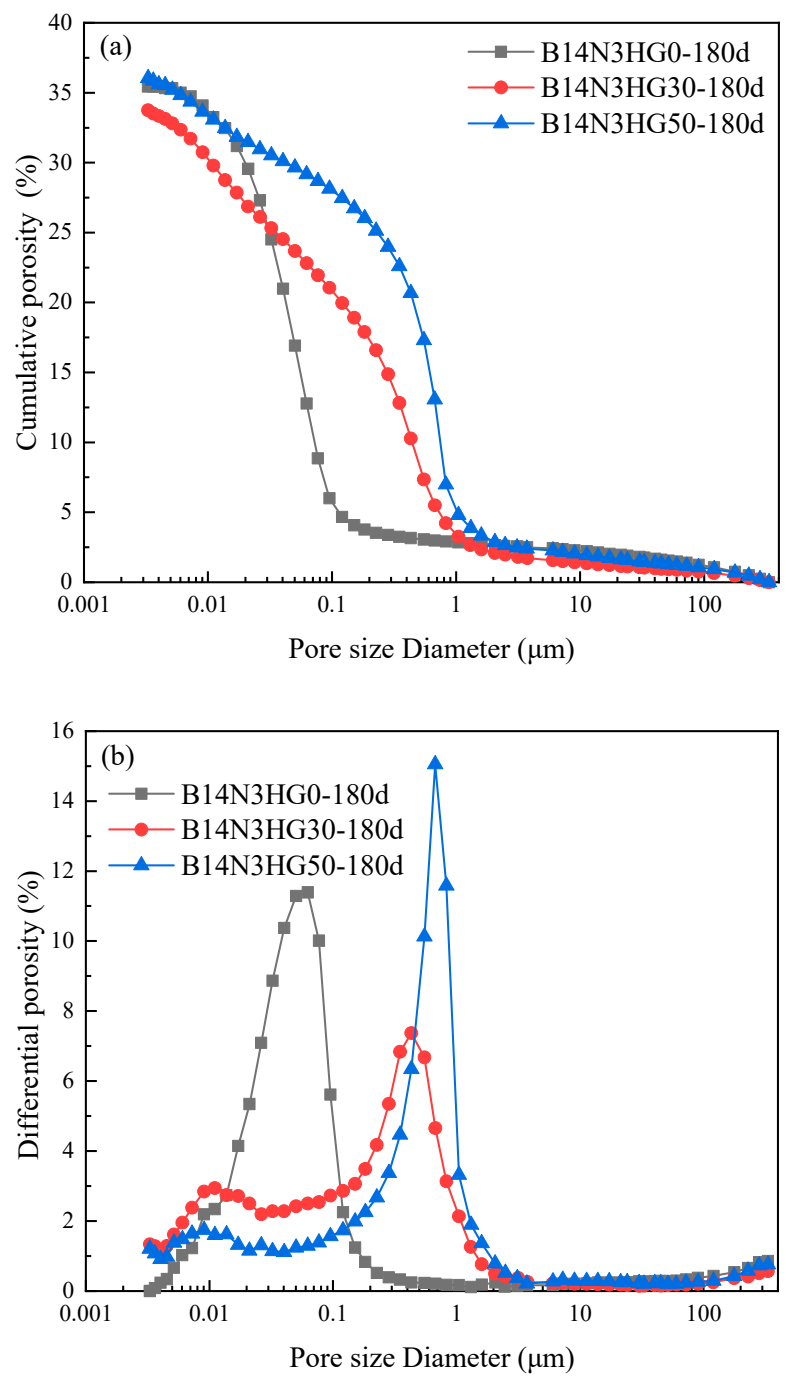

Figure 6. Cumulative porosity (a) and differential porosity (b) of NAS-HG-CPB at $180 \mathrm{~d}$. 
It can be seen from Figure $6 \mathrm{~b}$ that HG incorporation changes the pore distribution of the structure. The types (crystalline or amorphous) and contents of hydration products play an essential role by filling the voids in the tailings particles. With the increase in HG incorporation, the porosity associated with pores of sizes less than $0.1 \mu \mathrm{m}$ diameter decreased.

\subsection{Hydration Mechanism}

The hydration mechanism of NAS-HG-CPB involves a complex process, including the hydration reactions of the binders (i.e., HG and NAS) and the internal corrosion reactions associated with the oxidation of the sulphide phases present in the tailings. HG hydration is the process of absorbing water and converting it into dihydrate gypsum (DG). Most researchers agree that the process leading to DG formation involves a solution mechanism, which includes three stages: the dissolution of HG, the formation of DG nuclei and the crystallisation of DG [33]. The hydration mechanism of traditionally alkali-activated materials mainly includes the following steps: (1) the $\mathrm{OH}$ - ions in the alkaline solution are adsorbed on and into particles containing active components, breaking the bonds of $\mathrm{Ca}-\mathrm{O}$, $\mathrm{Al}-\mathrm{O}$ and $\mathrm{Si}-\mathrm{O}$, catalysing the hydrolysis of $\mathrm{Si} 4+$ and $\mathrm{Al} 3+$ and resulting in the formation of $\mathrm{Si}-\mathrm{OH}$ and $\mathrm{Al}-\mathrm{OH}$ species; (2) the dissolved $\mathrm{SiO} 4$ and $\mathrm{AlO} 4$ monomers polymerise into oligomers or gels; (3) the network of gels reorganises, further increasing the local structural order [34-37]. At present, there are no studies on the hydration mechanism of NAS-HG-CPB. However, the effect of the phosphogypsum (PG) in alkali-activated ground granulated blast furnace slag (GGBS) on the reactivity, strength development and long-stage matrix properties was investigated as a function of alkali activator [38]. The main conclusions are that (1) PG completely dissolved and took part in the solid reaction product formation, and a hydraulic binder was created; (2) the main hydration products are amorphous, intermixed with thenardite and minor amounts of secondary gypsum and undissolved merwinite. Combining the hydration mechanism of the existing HG and NAS as well as the results of this study, the hydration mechanism of NAS-HG-CPB can be proposed as follows:

The $\mathrm{NaOH}$ in NAS-HG-CPB dissolved and formed an alkaline solution when in contact of water, and the HG in NAS-HG-CPB absorbed water and was converted to dihydrate gypsum (DG, $\mathrm{CaSO}_{4} \bullet 2 \mathrm{H}_{2} \mathrm{O}$ ) with a certain solubility. The calcium, aluminium and sulphate anions dissolved from GGBS particles and primary DG can form crystalline phases at the early-stage ( $\leqq 28 \mathrm{~d}$ ). Simultaneously, the $\mathrm{Na}, \mathrm{Ca}, \mathrm{Al}$ and $\mathrm{Si}$ dissolved from the GGBS particles and $\mathrm{NaOH}$ polymerise into oligomers or gels. The network of gels reorganises, further increasing the local structural order to form amorphous phases. The crystalline products are ettringite $(\mathrm{AFt})$ and primary dihydrate gypsum. The amorphous phases are calcium-aluminosilicate-hydrate (C-A-S-H), intermixed with thenardite, minor amounts of secondary gypsum, and undissolved merwinite [38] and sodium-aluminosilicate-hydrate (N-A-S-H) [39].

When 30 wt. \% HG replaced NAS in NAS-HG-CPB, DG almost entirely took part in ettringite $(\mathrm{AFt})$ product formation, leading to the DG being undetected at $28 \mathrm{~d}$ (see Figure 4 b), and denser microstructures compared to the NAS-CPB without HG incorporation (see Figure 6). The formation of ettringite consumed the calcium and aluminium ions in the alkaline solution, resulting in the further dissolution of GGBS. It can be inferred that appropriate HG incorporation accelerates the hydration process of GGBS in the alkaline solution by forming ettringite (AFt). Therefore, the $28 \mathrm{~d}$ UCS of CPB with $30 \mathrm{wt}$. \% HG replacing NAS increased by $52 \%$ compared to that of $\mathrm{CPB}$ without $\mathrm{HG}$ incorporation. $\mathrm{CPBs}$ with $30 \mathrm{wt}$. \% HG replacing NAS and without HG incorporation have stable long-stage (180 d) UCS (i.e., no strength loss). The results are attributed to the dense microstructure resulting from the cumulated hydration products (see Figure $5 a, b$ ). The formation of hydration products has a significant effect on preventing the oxidation reaction of sulphide in NAS-HG-CPB. The effect of gypsum dosages between 0 and $30 \mathrm{wt}$. \% on the properties of cemented paste backfill using alkali-activated slag also needs to be further studied. 
When the excess HG ( $\geqq 50$ wt. \%) replaced NAS in NAS-HG-CPB, the DG did not fully participate in ettringite (AFt) product formation, leading to DG being detected at $28 \mathrm{~d}$ (see Figure 4c). In this stuy, the total binder (NAS and HG) dosage is $14 \%$ of the total solid content in CPB, and the NAS dosage in NAS-HG-CPB decreased with the increase in HG dosage. The $\mathrm{Na}, \mathrm{Ca}, \mathrm{Al}$ and $\mathrm{Si}$ were present in the NAS binder involved in the formation of amorphous hydration products. Therefore, the increase in HG dosage resulted in the reduction of the amorphous phase in NAS-HG-CPB, leading to the loose microstructure (see Figures $5 c$ and 6 ) and the $28 \mathrm{~d}$ UCS reduction. In addition, the NAS-HG-CPB with the excess HG has the unstable long-stage (180 d) UCS value compared with $28 \mathrm{~d}$ UCS, which is attributed to the formation of secondary gypsum (see Figure 4c).

From the technical benefits, we conclude that the NAS-HG binder with low dosages of HG ( $\leqq 30 \mathrm{wt}$. \%) is a promising binder for sulphide tailings, and other tailings such as iron ore tailings, as the NAS-HG-CPB has high early-stage strength. On the other hand, the waste gypsum (i.e., fluor gypsum, phosphogypsum and flue gas desulphurisation (FGD) gypsum) materials are readily available at low cost in China. Therefore, using NAS-HG as a binder in CPB will result in great economic and environmental benefits.

Additional research efforts are required to assess the effect of gypsum addition on heavy metal immobilisation in sulphide-rich cemented paste backfill. These studies may include the assessment of the potential toxicity of the produced NAS-HG-CPB by leaching tests [40-42] as well as mineralogical and microstructural analyses.

\section{Conclusions}

In this study, the effects of gypsum on the mechanical performance and microstructure of sulphide-rich cemented paste backfill using $\mathrm{NaOH}$-activated slag as binders were investigated. The dosage of HG does not influence the instant fluidity of fresh NAS-HG-CPB pastes. However, after resting for one hour, the greater the HG content, the lower the fluidity value is. The incorporation of $30 \mathrm{wt}$. \% HG replacing the NAS in NAS-HG-CPB accelerates the hydration process of GGBS in the alkaline solution by forming ettringite (AFt), leading to a denser microstructure. The CPB with $30 \mathrm{wt}$ \% HG had a $28 \mathrm{~d}$ UCS value that was increased by $52 \%$ compared with the CPB containing no HG. CPBs with $30 \mathrm{wt}$. \% HG and without HG incorporation have stable long-stage $(180 \mathrm{~d})$ UCS values (i.e., no strength loss), which is attributed to the dense microstructures due to the formation of hydration products. A high HG dosage ( $\geqq 50 \mathrm{wt}$. \%) reduced the CPB $28 \mathrm{~d}$ UCS value, which resulted from the loose microstructure caused by the decrease in amorphous hydration products, and led to the unstable long-stage (180 d) UCS vaue due to the formation of secondary gypsum. The main hydration products of NAS-HG-CPB derived from sulphide-rich tailings are crystalline (ettringite $\left.(\mathrm{AFt}), \mathrm{CaSO}_{4} \bullet 2 \mathrm{H}_{2} \mathrm{O}\right)$ and amorphous hydration products, intermixed with thenardite and minor amounts of secondary gypsum and undissolved merwinite.

Besides this, using NAS-HG as a binder in CPB can result in significant economic and environmental benefits, such as providing a new solution for waste gypsum utilisation. The effects of gypsum dosages between 0 and $30 \mathrm{wt}$. \% on the performance of cemented paste backfill using $\mathrm{NaOH}$-activated slag as binders, as well as whether the sulphur present in in the tailings is involved in the formation of secondary gypsum, should be subjects of further investigation. The potential toxicity of the NAS-HG-CPB produced by the toxicity characteristics leaching procedure (TCLP) should also be carefully assessed.

Author Contributions: Conceptualization, L.G. and J.Z.; methodology, Y.T.; formal analysis, Y.T.; writing-original draft preparation, Y.T.; writing—review and editing, Y.Z.; supervision, L.G.; funding acquisition, L.G. All authors have read and agreed to the published version of the manuscript.

Funding: This research was funded by the State Key Research Development Program of China, grant number 2018YFE0123000 and The APC was funded by the National Natural Science Foundation of China, grant number 51774040 .

Data Availability Statement: Not applicable. 
Conflicts of Interest: The authors declare no conflict of interest.

\section{References}

1. Chen, Y.; Chen, B.H.; Zhou, Q. Distribution of heavy metals in water-surface sediments in AMD, Dabao Mountain in North Guangdong Province and influential factors. J. Environ. Sci. 2018, 38, 134-141. (In Chinese) [CrossRef]

2. Plante, B.; Bussière, B.; Benzaazoua, M. Lab to field scale effects on contaminated neutral drainage prediction from the Tio mine waste rocks. J. Geochem. Explor. 2014, 137, 37-47. [CrossRef]

3. Genty, T.; Bussière, B.; Potvin, R.; Benzaazoua, M.; Zagury, G.J. Dissolution of calcitic marble and dolomitic rock in high iron concentrated acid mine drainage: Application to anoxic limestone drains. Environ. Earth Sci. 2012, 66, 2387-2401. [CrossRef]

4. Yilmaz, E. Advances in reducing large volumes of environmentally harmful mine waste rocks and tailings. Miner. Resour. Manag. 2011, 27, 89-112.

5. Qi, C.C.; Fourie, A. Cemented paste backfill for mineral tailings management: Review and future perspectives. Miner. Eng. 2019, 144, 1-21. [CrossRef]

6. Ercikdi, B.; Cihangir, F.; Kesimal, A.; Deveci, H. Practical importance of tailings for cemented paste backfill. In Paste Tailings Management; Springer International Publishing: Cham, Switzerland, 2017; pp. 7-32.

7. Mangane, M.B.C.; Argane, R.; Trauchessec, R.; Lecomte, A.; Benzaazoua, M. Influence of superplasticisers on mechanical properties and workability of cemented paste backfill. Miner. Eng. 2018, 116, 3-14. [CrossRef]

8. Yilmaz, E.; Fall, M. Paste Tailings Management; Springer International Publishing: Cham, Switzerland, 2017; 303p.

9. Ouellet, S.; Bussière, B.; Aubertin, M.; Benzaazoua, M. Microstructural evolution of cemented paste backfill: Mercury intrusion porosimetry test results. Cem. Concr. Res. 2007, 37, 1654-1665. [CrossRef]

10. Tariq, A.; Nehdi, M. Developing durable paste backfill from sulphidic tailings. Waste Resour. Manag. 2007, 160, 155-166. [CrossRef]

11. Yin, S.; Shao, Y.; Wu, A.; Wang, Y.; Chen, X. Expansion and strength properties of cemented backfill using sulphidic mill tailings. Construct. Build. Mater. 2018, 165, 138-148. [CrossRef]

12. Cihangir, F.; Akyol, Y. Mechanical, hydrological and microstructural assessment of the durability of cemented paste backfill containing alkali-activated slag. Int. J. Min. Reclamat. Environ. 2018, 32, 123-143. [CrossRef]

13. Atis, C.D.; Bilim, C.; Çelik, Ö.; Karahan, O. Influence of activator on the strength and drying shrinkage of alkali-activated slag mortar. Constr. Build. Mater. 2009, 23, 548-555. [CrossRef]

14. Bondar, D.; Lynsdale, C.J.; Milestone, N.B.; Hassani, N.; Ramezanianpour, A.A. Effect of type, form, and dosage of activators on strength of alkali-activated natural pozzolans. Cem. Concr. Res. 2011, 33, 251-260. [CrossRef]

15. Bakharev, T. Resistance of geopolymer materials to acid attack. Cem. Concr. Res. 2005, 35, 658-670. [CrossRef]

16. Shi, C.; Krivenko, P.V.; Roy, D. Alkali-Activated Cements and Concretes, 1st ed.; Taylor and Francis: Abingdon, UK, 2006.

17. Walia, M.K.; Dick, W.A. Selected soil physical properties and aggregate-associated carbon and nitrogen as influenced by gypsum, crop residue, and glucose. Geoderma 2018, 320, 67-73. [CrossRef]

18. Hua, S.; Wang, K.; Yao, X.; Xu, W.; He, Y. Effects of fibers on mechanical properties and freeze-thaw resistance of phosphogypsumslag based cementitious materials. Constr. Build. Mater. 2016, 121, 290-299. [CrossRef]

19. Hao, Y.; Wu, S.; Pan, Y.; Li, Q.; Zhou, J.; Xu, Y.; Qian, G. Characterisation and leaching toxicities of mercury in flue gas desulfurisation gypsum from coal-fired power plants in China. Fuel 2016, 177, 157-163. [CrossRef]

20. Al Attar, L.; Al-Oudat, M.; Kanakri, S.; Budeir, Y.; Hussam Khalily, H.; Al Hamwi, A. Radiological impacts of phosphogypsum. J. Environ. Manag. 2011, 92, 2151-2158. [CrossRef]

21. Hammas, I.; Horchani-Naifer, K.; Férid, M. Solubility study and valorization of phosphogypsum salt solution. Int. J. Miner. Process. 2013, 123, 87-93. [CrossRef]

22. Hammas-Nasri, I.; Horchani-Naifer, K.; Férid, M.; Donatella Barca, D. Rare earths concentration from phosphogypsum waste by two-step leaching method. Int. J. Miner. Process. 2016, 149, 78-83. [CrossRef]

23. Zhou, J.; Gao, H.; Shu, Z.; Wang, Y.X.; Yan, C.J. Utilization of waste phosphogypsum to prepare non-fired bricks by a novel Hydration-Recrystallization process. Constr. Build. Mater. 2012, 34, 114-119. [CrossRef]

24. Ding, W.J.; Chen, Q.J.; Hongjuan Sun, H.J.; Peng, T.J. Modified mineral carbonation of phosphogypsum for $\mathrm{CO}_{2}$ sequestration. J. $\mathrm{CO}_{2}$ Util. 2019, 34, 507-515. [CrossRef]

25. Liu, S.H.; Wang, L.; Yu, B.Y. Effect of modified phosphogypsum on the hydration properties of the phosphogypsum-based supersulfated cement. Constr. Build. Mater. 2019, 214, 9-16. [CrossRef]

26. Peyronnard, O.; Benzaazoua, M. Estimation of the cementitious properties of various industrial by-products for applications requiring low mechanical strength. Resour. Conserv. Recycl. 2011, 56, 22-33. [CrossRef]

27. Jiang, G.Z.; Wu, A.X.; Wang, Y.M.; Lan, W.T. Low cost and high efficiency utilisation of hemihydrate phosphogypsum: Used as binder to prepare filling material. Constr. Build. Mater. 2018, 167, 263-270. [CrossRef]

28. Cihangir, F.; Ercikdi, B.; Kesimal, A.; Ocak, S.; Akyol, Y. Effect of sodium-silicate activated slag at different silicate modulus on the strength and microstructural properties of full and coarse sulphidic tailings paste backfill. Constr. Build. Mater. 2018, 185, 555-566. [CrossRef]

29. Rubert, S.; Luz, C.A.; Varela, M.V.F.; Filho, J.I.P.; Hooton, R.D. Hydration mechanisms of supersulfated cement: The role of alkali activator and calcium sulfate content. J. Therm. Anal. Calorim. 2018, 134, 971-980. [CrossRef] 
30. Landriault, D. Backfill in underground mining. In Underground Mining Methods: Engineering Fundamentals and International Case Studies; Society for Mining, Metallurgy, and Exploration: Englewood, CO, USA, 2001; pp. 601-614.

31. Fall, M.; Benzaazoua, M.; Ouellet, S. Effect of tailings properties on paste backfill performance. In Proceedings of the International Symposium on Mining with Backfill, Beijing, China, 19-21 September 2004; pp. 193-202. Available online: https://www. researchgate.net/publication/265273604_Effect_of_tailings_properties_on_paste_backfill_performance (accessed on 28 February 2021).

32. Zheng, J.R.; Lv, S.S.; Zhao, Z.B. Method for determination of fluidity of paste slurry of whole tailings. Min. Technol. 2013, 13, 23-25. (In Chinese) [CrossRef]

33. Kaziliunas, A.; Leskeviciene, V.; Vektaris, B.; Valancius, Z. The study of neutralisation of the dihydrate phosphogypsum impurities. Ceram-Silik. 2006, 50, 178-184.

34. Wang, S.; Scrivener, K.; Pratt, P. Factors affecting the strength of alkali-activated slag. Cem. Concr. Res. 1994, $24,1033-1043$. [CrossRef]

35. Komnitsas, K.; Yurramendi, L.; Bartzas, G.; Karmali, V.; Petrakis, E. Factors affecting co-valorization of fayalitic and ferronickel slags for the production of alkali activated materials. Sci. Total Environ. 2020, 721, 137753. [CrossRef]

36. Cui, Y.; Wang, D.M.; Wang, Y.R.; Sun, R.; Rui, Y.F. Effects of the $\mathrm{n}\left(\mathrm{H}_{2} \mathrm{O}: \mathrm{Na}_{2} \mathrm{Oeq}\right)$ ratio on the geopolymerization process and microstructures of fly ash-based geopolymers. J. Non-Cryst. Solids 2019, 511, 19-28. [CrossRef]

37. Fernandez-Jimenez, A.; Cristelo, N.; Miranda, T.; Palomoa, A. Sustainable alkali activated materials: Precursor and activator derived from industrial wastes. J. Clean. Prod. 2017, 162, 1200-1209. [CrossRef]

38. Gijbels, K.; Iacobescu, R.I.; Pontikes, Y.; Schreurs, S.; Schroeyers, W. Alkali-activated binders based on ground granulated blast furnace slag and phosphogypsum. Constr. Build. Mater. 2019, 215, 371-380. [CrossRef]

39. Komnitsas, K.; Zaharaki, D.; Bartzas, G. Effect of sulphate and nitrate anions on heavy metal immobilisation in ferronickel slag geopolymers. Appl. Clay Sci. 2013, 73, 103-109. [CrossRef]

40. Komnitsas, K.; Petrakis, E.; Bartzas, G.; Karmali, V. Column leaching of low-grade saprolitic laterites and valorization of leaching residues. Sci. Total Environ. 2019, 665, 347-357. [CrossRef] [PubMed]

41. EN12457-3. Characterization of Waste—Compliance Test for Leaching of Granular Waste Materials and Sludges—Part 3: Two Stage Batch Test at a Liquid to Solid Ratio of $2 \mathrm{l} / \mathrm{kg}$ and $8 \mathrm{l} / \mathrm{kg}$ for Materials with High Solid Content and With Particle Size Below $4 \mathrm{~mm}$; European Committee for Standardization: Brussels, Belgium, 2002.

42. Van der Sloot, H.A.; Hjelmar, O.; Bjerre Hansen, J.; Woitke, P.; Lepom, P.; Leschber, R.; Bartet, B.; Debrucker, N. Validation of CEN/TC 292 Leaching Tests and Eluate Analysis Methods prEN 12457 1-4, ENV 13370 and ENV 12506. 2001. Available online: https:/ / repository.tno.nl/ / islandora/object/uuid:d49a977b-011d-46fa-96cd-045623e8a8ad (accessed on 28 February 2021). 